\title{
PATIENT SATISFACTION WITH ORTHOPEDIC AND PROSTHETIC MEDICAL DEVICES
}

\author{
Ivona Malovecká ${ }^{1}$, Daniela Mináriková ${ }^{2}$, Viliam Foltán ${ }^{3}$
}

\begin{abstract}
Collecting information about patient satisfaction with orthopedic and prosthetic medical devices in terms of utility, tolerance, and compliance is essential for verifying and improving the quality of these devices. In addition, such information is useful for improving the patients' quality of life, and the quality management systems of health care providers. This study assessed patient satisfaction with these devices from a sample of patients with orthopedic, neurologic, and rheumatic diseases at the Specialized Hospital for Orthopedic Prosthetics and at the premises of the Dispenser of Orthopedic and Prosthetic Medical Devices, both in Bratislava in the Slovak Republic. The assessment involved a translated and validated questionnaire about patient satisfaction with orthopedic and prosthetic medical devices to evaluate key factors of weight, fit, appearance, comfort, pain free, free of abrasiveness, ease of application, and durability of each device. The study samples consisted of patients with lower limb problems (42.5\%), spine problems (26.9\%), and a combination of leg and spine issues (25.9\%). Orthopedic disease occurred in $73.6 \%$ of these patients, a combination of orthopedic and neurologic disease in $13.5 \%$, and neurologic disease in 7.3\%. Orthopedic insoles (36.3\%), hip belts (17.6\%), and the corset on the spine $(5.2 \%)$ were the most used devices. Overall, the medical devices rated highly, with a high proportion of patients voting "strongly satisfied" in five of the eight key factors (range 51.8 to $63.2 \%$ ), followed by a moderately lower proportion for durability $(43.5 \%)$, comfort $(37.3 \%)$, and appearance $(31.1 \%)$. The comfort in wearing the device received the greatest patient dissatisfaction (22.8\% of patients), followed by appearance (12.4\%), and then fit $(7.3 \%)$.
\end{abstract}

JEL Classification Numbers: I19, DOI: http://dx.doi.org/10.12955/cbup.v3.632

UDC Classification: 617.3

Keywords: Orthopedics, prosthetic, medical device, patient satisfaction, quality, patient quality of life, quality management, health care provider

\section{Introduction}

Medical devices are products intended for use in the diagnosis, mitigation, treatment, or prevention of a disease that could affect the structure or function of the human body or of other animals (FDA, 2014). The health status of people with physical disabilities often requires orthopedic and prosthetic medical devices. These act to support muscle weakness, immobilize or stabilize the joint, facilitate movement of tendons, remodel scars, remove restrictions on movement, strengthen certain muscle groups to avoid distortions, or support other tools of everyday life (Sastri, 2014). The orthotic and prosthetic treatment options increase with technological progress and many patients need to wear their orthosis and prosthesis for a long period, and, for some, their entire life. Therefore, the collection of information on patient satisfaction with orthopedic and prosthetic medical devices (OPMD) in terms of tolerance and compliance is essential for verifying and improving these devices, and improving the patients' quality of life (Bravini et al, 2014). Additionally, the information is useful for assessing the quality of management systems of the health care provider. To assess patient satisfaction with orthopedic and prosthetic medical devices, a special questionnaire was developed and validated using psychometric tests. The Orthotics and Prosthetics Users' Survey (OPUS) was identified by a systematic literary review as the only tool designed for evaluating patient satisfaction with medical devices. This tool has five separate modules: 1) functional state of the lower limbs; 2) functional status of the upper limbs; 3) client satisfaction with medical devices (CSD); 4) client satisfaction with the services; and 5) health-related quality of life. Module 3, the client satisfaction with medical devices, can be used separately to assess

\footnotetext{
${ }^{1}$ Ivona Malovecká, Faculty of Pharmacy, Department of Organization and Management in Pharmacy, Comenius University in Bratislava, Slovak republic, ivonamalovecka@gmail.com, malovecka@fpharm.uniba.sk

2 Daniela Mináriková, Faculty of Pharmacy, Department of Organization and Management in Pharmacy, Comenius University in Bratislava, Slovak republic, minarikova@fpharm.uniba.sk

${ }^{3}$ Viliam Foltán, Faculty of Pharmacy, Department of Organization and Management in Pharmacy, Comenius University in Bratislava, Slovak republic, foltan@fpharm.uniba.sk
} 
patient satisfaction with the OPMD. This questionnaire was originally developed in English (Heinemann, Bode, \& O'Reilly, 2003). It was later translated and validated in Swedish (Jarl \& Hermansson, 2009; Jarl, Heinemann, \& Hermansson, 2012; Jarl, Holmefur, \& Hermansson, 2014), and then into Slovak language before rigorous psychometric validation. The resulting modified module for patient satisfaction with OPMD showed a degree of validity and reliability, with eight key factors of weight, fit, appearance, comfort, pain free, free of abrasiveness, easy of application and durability of OPMD to assess.

\section{Research Goal}

This study assessed patient satisfaction with orthopedic and prosthetic medical devices through a translated, territorially adapted, and validated questionnaire on patients' satisfaction with these devices. The aim was to identify the key factors affecting their use and satisfaction. Such an assessment had not been previously carried out in Slovakia. The results of this study will be submitted and presented to the Specialized Hospital for Orthopedic Prosthetics (SNOP; Non-profit Organization) and the Dispenser of Orthopedic and Prosthetic Medical Devices (NEOPROT; Limited Liability Company), as an indication of the quality of health care provided by health care facilities, and as an impetus for enhancing the compulsory quality management systems of health care providers (ISO).

\section{Research Experiment}

\section{Location and timing}

Assessment of patient satisfaction with OPMD took place at the premises of the SNOP (Limited Liability Company) and that of the NEOPROT (Limited Liability Company), Záhradnícka Street in Bratislava, Slovak Republic, between November and December 2014, after approval given by the head of the institutions.

\section{The target group}

The patient selection criteria were that subjects were at least 18 years of age, and that they routinely used orthopedic and prosthetic medical devices for a neurologic, orthopedic, or rheumatic disease. In total, 215 people were invited to participate. Of these, 193 responded with completed questionnaires for evaluation. The clinical and demographic characteristics of different sets of patients are presented in Table 1 .

\begin{tabular}{|c|c|c|}
\hline Characteristics & \multicolumn{2}{|c|}{ Number of Patients } \\
\hline \multicolumn{3}{|l|}{ Age } \\
\hline$<41$ & 55 & $28.5 \%$ \\
\hline $41-60$ & 48 & $24.9 \%$ \\
\hline$>60$ & 90 & $46.6 \%$ \\
\hline Total & 193 & $100.0 \%$ \\
\hline \multicolumn{3}{|l|}{ Gender } \\
\hline Men & 48 & $24.9 \%$ \\
\hline Women & 145 & $75.1 \%$ \\
\hline Total & 193 & $100.0 \%$ \\
\hline \multicolumn{3}{|l|}{ Education } \\
\hline Basic school & 23 & $11.9 \%$ \\
\hline
\end{tabular}


CBU INTERNATIONAL CONFERENCE ON INNOVATION, TECHNOLOGY TRANSFER AND EDUCATION

\begin{tabular}{|l|r|r|}
\hline High school & 108 & $56.0 \%$ \\
\hline University & 62 & $32.1 \%$ \\
\hline Total & 193 & $100.0 \%$ \\
\hline Disease & & \\
\hline Orthopedic & 142 & $73.6 \%$ \\
\hline Orthopedic, neurologic & 26 & $13.5 \%$ \\
\hline Orthopedic, rheumatologic & 5 & $2.6 \%$ \\
\hline Neurologic & 14 & $7.3 \%$ \\
\hline Rheumatologic & 1 & $0.5 \%$ \\
\hline Orthopedic neurologic, rheumatologic & 5 & $2.6 \%$ \\
\hline Total & $\mathbf{1 9 3}$ & $\mathbf{1 0 0 . 0 \%}$ \\
\hline Source: Authors & & \\
\hline
\end{tabular}

Most patients were older than 60 years of age $(n=90 ; 46.6 \%)$, and of these $145(75.1 \%)$ were women. The highest level of patient education was secondary level $(\mathrm{n}=108 ; 56.0 \%)$. The most common type of disease was orthopedic $(n=142 ; 73.6 \%)$, followed by the combination of orthopedic and neurologic disorders $(n=26 ; 13.5 \%)$.

The most common position for use of an OPMD was on the lower limbs (42.5\%), followed by the spine (26.9\%) and then the spine and lower limbs (25.9\%). There were 3.6\% patients with an OPMD applied to their upper limbs, and $1.0 \%$ had an OPMD on lower and upper limbs, and the spine, simultaneously (Table 2).

\begin{tabular}{|l|r|r|}
\hline \multicolumn{2}{|c|}{ Table 2: Orthopedic and prosthetic medical device location of use / application } \\
\hline \multicolumn{1}{|c|}{ Districts } & \multicolumn{2}{|c|}{ Number of patients } \\
\hline Upper limbs & 7 & $3.6 \%$ \\
\hline Lower limbs & 82 & $42.5 \%$ \\
\hline Lower limbs, Spine & 50 & $25.9 \%$ \\
\hline Spine & 52 & $26.9 \%$ \\
\hline Lower limbs, Upper limbs, Spine & 2 & $1.0 \%$ \\
\hline Total & $\mathbf{1 9 3}$ & $\mathbf{1 0 0 . 0 \%}$ \\
\hline Source: Authors & & \\
\hline
\end{tabular}

\begin{tabular}{|l|l|l|l|}
\hline \multicolumn{3}{|l|}{$\begin{array}{l}\text { Table 3: The most common types of orthopedic and prosthetic medical devices and its mean duration of use in } \\
\text { the group of patients }\end{array}$} & $\begin{array}{c}\text { Mean duration of use } \\
\text { (years) }\end{array}$ \\
\hline \multicolumn{1}{|c|}{$\begin{array}{c}\text { Type of orthosis and prosthesis } \\
\text { medical device }\end{array}$} & Number of patients & 5.0 \\
\hline Orthopedic insoles & 70 & $36.3 \%$ & 4.2 \\
\hline Waist belt & 34 & $17.6 \%$ & 3.9 \\
\hline Orthopedic stick & 15 & $7.8 \%$ & 2.3 \\
\hline Corset on the spine & 10 & $5.2 \%$ & 3.0 \\
\hline French crutches & 9 & $4.7 \%$ & 2.5 \\
\hline Cervical collar & 9 & $4.7 \%$ & 2.2 \\
\hline Knee bandage & 4 & $2.1 \%$ & \\
\hline
\end{tabular}


CBU INTERNATIONAL CONFERENCE ON INNOVATION, TECHNOLOGY TRANSFER AND EDUCATION

\begin{tabular}{|l|l|l|l|}
\hline Orthopedic shoes & 4 & $2.1 \%$ & 5.0 \\
\hline Knee brace & 3 & $1.6 \%$ & 2.2 \\
\hline Prosthesis legs & 3 & $1.6 \%$ & 16.0 \\
\hline Source: Authors & & & \\
\hline
\end{tabular}

The orthopedic insoles (36.3\%) were the most widely used OPMD, with a mean duration of use of 5 years. About half of these patients with orthopedic insoles (17.6\%) used the waist belt, which had an average duration of use of 4.2 years. Next was the orthopedic stick, used by $7.8 \%$ of patients, which had a mean duration of use of almost 4 years. The corset on the spine was used about $5 \%$ of patients and had a mean duration of use of over 2 years. The French crutches and cervical collars were used by a similar number of patients (4.7\%), with the mean duration of use of these being 2 and 2.5 years, respectively. The knee bandage and orthopedic shoes were used by $2.1 \%$ of patients, with the mean duration of these being approximately 2 and 5 years, respectively. The brace on the knee and prosthesis on the legs was used by only $1.6 \%$ of patients, but the mean duration of use the prosthesis was up to 16 years (Table 3).

\section{Rating method}

The study used a module for client satisfaction that involved a generic self-administered questionnaire, which asked patients about their satisfaction with the use of OPMD. The module was constructed by examining individual items from a number of published instruments and was subsequently improved and revised with items that tested a user's satisfaction. The module contained eight key factors that evaluated weight, durability, pain free, free of abrasiveness, comfort, appearance, fit and ease of application of the OPMD using a four-level Likert scale: 1 strongly agree/very satisfied, 2 agree/satisfied, 3 disagree/dissatisfied, and 4 strongly disagree/very dissatisfied. The Slovak version of the revised eight key factors was used for the module on patient satisfaction with orthopedic and prosthetic medical devices. The patient satisfaction with OPMD was also based and evaluated on the Likert scale, which is considered one of the most reliable measurement techniques on attitudes because it uses a one-dimensional approach.

\section{Results}

The assessment of patient satisfaction with OPMD rated the key factors: weight, fit, appearance, comfort, pain free, free of abrasiveness, ease of application, and durability of the devices. Overall, the patients $(n=193)$, with a mean age of 54 years, used an OPMD for a mean duration of four years. The total satisfaction for each key factor ranged between 1 and 2, while, as a whole, patient satisfaction with OPMD was 1.6 on average. Hence, to avoid a biased interpretation, it is necessary to analyze individual items as well as the different types of OPMD, in terms of their characteristics.

The patients were highly satisfied (strongly agree) with the weight (63.2\%), fit (53.4\%) and free of abrasiveness (53.4\%), but were dissatisfied (disagree) with comfort (22.3\%) and appearance (12.4\%) of the OPMD. Only one patient was highly dissatisfied (strongly disagree). The patients were completely satisfied (strongly agree and agree) in terms of the weight (99.5\%), fit (92.8\%), durability (93.3\%), pain free (94.8\%), free of abrasiveness (93.8\%), and ease of application (95.8\%). Despite the relatively high levels of dissatisfaction in comfort $(22.8 \%)$ and appearance $(12.4 \%)$, the total satisfaction (strongly agree and agree) was $77.2 \%$ and $87.6 \%$ for these, respectively. The overall patient satisfaction (strongly agree and agree) ranged between $99.5 \%$ and $77.2 \%$ in all evaluated factors. The overall dissatisfaction with OPMD (disagree and strongly disagree) ranged between $0.5 \%$ and $7.3 \%$, for all evaluated factors except comfort (22.3\%) and appearance (12.4\%), which departed from the trend in patient dissatisfaction observed with other factors. The corset for the spine contributed mostly to the negative ratings for OPMD. The mean age of the wearers was 23.5 years, and the mean duration of use was 2.3 years for 
CBU INTERNATIONAL CONFERENCE ON INNOVATION, TECHNOLOGY TRANSFER AND EDUCATION

this device. These patients were comparatively young and wore the OPMD for lengthy durations. The assessment results of patient satisfaction with OPMD for the different factors are given in Table 4

\begin{tabular}{|c|c|c|}
\hline Characteristics of OPMD & \multicolumn{2}{|c|}{ Number of patients } \\
\hline \multicolumn{3}{|l|}{ Weight of OPMD is manageable } \\
\hline Strongly agree & 122 & $63.2 \%$ \\
\hline Agree & 70 & $36.3 \%$ \\
\hline Disagree & 1 & $0.5 \%$ \\
\hline Total & 193 & $100.0 \%$ \\
\hline \multicolumn{3}{|l|}{ OPMD fits well } \\
\hline Strongly agree & 103 & $53.4 \%$ \\
\hline Agree & 76 & $39.4 \%$ \\
\hline Disagree & 14 & $7.3 \%$ \\
\hline Total & 193 & $100.0 \%$ \\
\hline \multicolumn{3}{|l|}{ OPMD is durable } \\
\hline Strongly agree & 84 & $43.5 \%$ \\
\hline Agree & 96 & $49.7 \%$ \\
\hline Disagree & 13 & $6.7 \%$ \\
\hline Total & 193 & $100.0 \%$ \\
\hline \multicolumn{3}{|l|}{ OPMD is pain free to wear } \\
\hline Strongly agree & 100 & $51.8 \%$ \\
\hline Agree & 83 & $43.0 \%$ \\
\hline Disagree & 10 & $5.2 \%$ \\
\hline Total & 193 & $100.0 \%$ \\
\hline \multicolumn{3}{|l|}{ OPMD is free of abrasiveness } \\
\hline Strongly agree & 103 & $53.4 \%$ \\
\hline Agree & 78 & $40.4 \%$ \\
\hline Disagree & 12 & $6.2 \%$ \\
\hline Total & 193 & $100.0 \%$ \\
\hline \multicolumn{3}{|l|}{ Easy to put on my OPMD } \\
\hline Strongly agree & 100 & $51.8 \%$ \\
\hline Agree & 85 & $44.0 \%$ \\
\hline Disagree & 8 & $4.1 \%$ \\
\hline Total & 193 & $100.0 \%$ \\
\hline \multicolumn{3}{|l|}{ OPMD is comfortable throughout the day } \\
\hline Strongly agree & 72 & $37.3 \%$ \\
\hline Agree & 77 & $39.9 \%$ \\
\hline Disagree & 43 & $22.3 \%$ \\
\hline Strongly disagree & 1 & $0.5 \%$ \\
\hline Total & 193 & $100.0 \%$ \\
\hline \multicolumn{3}{|l|}{ OPMD looks good } \\
\hline Strongly agree & 60 & $31.1 \%$ \\
\hline Agree & 109 & $56.5 \%$ \\
\hline
\end{tabular}




\begin{tabular}{|l|c|c|}
\hline Disagree & 24 & $12.4 \%$ \\
\hline Total & 193 & $100.0 \%$ \\
\hline Source: Authors & \\
\hline
\end{tabular}

The largest group of OPMD that were rated on a scale of 1 to 4 (1 - very satisfied, 2 - satisfied 3 dissatisfied, 4 - very dissatisfied), was the group, orthopedic insoles $(n=70 ; 36.3 \%)$, This had a mean age of patients of 49.1 years, an average duration of use of 5 years, and a very good overall patient satisfaction with OPMD (1.52; Table 5). Weight had the most positive rating (1.26). The worst rating was assigned to appearance (1.74), and then comfort (1.71). The second most numerous group of OPMD involved the waist belt, with a mean age of patients of 63 years, an average duration of use of 4 years, and a very good overall patient satisfaction with OPMD (1.53). The most positive rating for this group was attributed to weight (1.32), while appearance (1.85) and comfort (1.76) had the worst ratings. The third most numerous type of OPMD was corset on the spine, which had a mean age of patients of 23 years, an average time of duration of 2 years, and a good overall patient satisfaction with OPMD (2.13). Weight (1.90) received the most positive rating for this group, and comfort the worst (2.60). In some groups of OPMD, the extent of older patients coincided with high patient satisfaction with the device. For example, the waist belt had a mean age of patients of 63 years, an average duration of use of 4 years and a relatively high overall satisfaction rating of 1.53 .

\begin{tabular}{|c|c|c|c|c|c|c|c|c|}
\hline $\begin{array}{c}\text { Orthopedic and prosthetic } \\
\text { medical device }\end{array}$ & \multicolumn{2}{|c|}{$\begin{array}{l}\text { Orthopedic } \\
\text { insoles }\end{array}$} & \multicolumn{2}{|c|}{ Waist belt } & \multicolumn{2}{|c|}{$\begin{array}{l}\text { Corset on the } \\
\text { spine }\end{array}$} & \multicolumn{2}{|c|}{ Total } \\
\hline Patients n (n \%) & \multicolumn{2}{|c|}{$\mathrm{N}=70(36.27 \%)$} & \multicolumn{2}{|c|}{$\mathrm{N}=34(17.62 \%)$} & \multicolumn{2}{|c|}{$\mathrm{N}=10(5.18 \%)$} & \multicolumn{2}{|c|}{$\mathrm{N}=193(100 \%)$} \\
\hline $\begin{array}{l}\text { Demographic } \\
\text { characteristics }\end{array}$ & Mean & $\sigma$ & Mean & $\sigma$ & Mean & $\sigma$ & Mean & $\sigma$ \\
\hline Age & 49.10 & 27.65 & 63.03 & 11.33 & 23.50 & 15.99 & 54.08 & 20.83 \\
\hline $\begin{array}{l}\text { Duration of use OPMD } \\
\text { (years) }\end{array}$ & 5.02 & 0.00 & 4.16 & 3.46 & 2.28 & 2.50 & 4.46 & 6.63 \\
\hline \multicolumn{9}{|l|}{ Characteristics OPMD } \\
\hline $\begin{array}{l}\text { Weight of OPMD is } \\
\text { manageable }\end{array}$ & 1.26 & 0.44 & 1.32 & 0.53 & 1.90 & 0.32 & 1.30 & 0.50 \\
\hline OPMD fits well & 1.50 & 0.61 & 1.38 & 0.55 & 2.00 & 0.00 & 1.54 & 0.63 \\
\hline OPMD is durable & 1.59 & 0.60 & 1.56 & 0.56 & 2.00 & 0.47 & 1.63 & 0.61 \\
\hline $\begin{array}{l}\text { OPMD is pain free to } \\
\text { wear }\end{array}$ & 1.50 & 0.58 & 1.38 & 0.49 & 2.20 & 0.42 & 1.53 & 0.60 \\
\hline Skin free of abrasion & 1.40 & 0.55 & 1.47 & 0.56 & 2.10 & 0.32 & 1.53 & 0.61 \\
\hline Easy to put on OPMD & 1.44 & 0.56 & 1.53 & 0.56 & 2.10 & 0.57 & 1.52 & 0.58 \\
\hline $\begin{array}{l}\text { OPMD is comfortable } \\
\text { throughout the day }\end{array}$ & 1.71 & 0.74 & 1.76 & 0.07 & 2.60 & 0.52 & 1.86 & 0.77 \\
\hline OPMD looks good & 1.74 & 0.65 & 1.85 & 0.56 & 2.10 & 0.32 & 1.81 & 0.63 \\
\hline Total satisfaction & 1.52 & 0.45 & 1.53 & 0.41 & 2.13 & 0.25 & 1.60 & 0.64 \\
\hline \multicolumn{9}{|l|}{$\sigma-$ Standard deviation } \\
\hline uthors & & & & & & & & \\
\hline
\end{tabular}

Overall, the patients approached the survey positively. They appreciated the efforts by health care providers to obtain information on patient satisfaction with orthopedic and prosthetic medical devices. 
They positively evaluated the interest of the medical facility in the patient and their perception of the quality of services provided.

\section{Discussion}

A literature search had revealed a low incidence of publications relating to patient satisfaction in terms of orthopedic and prosthetic medical devices. Publications in this area tended to focus on the tool for assessment in regards to varying the methodology, translating or adapting it for other languages, or nationally validating the process. Those that evaluated patient satisfaction with OPMD, related to demographics that were contrary to the information held on the patient files of this study. For example, one study rated similar OPMD factors of weight, fit, durability, pain free, free of abrasiveness, ease of application, comfort, and appearance, but the patients were veterans of the Vietnam War, who had loss of limbs (Berke et al., 2010). Another example was a study that evaluated OPMD for patients with loss of lower limbs (Karmarkar et al., 2009). Once again, these were a different patient group to that of this study. Devices for limb prosthesis were the least applied in our study. Another two studies evaluated patient satisfaction relating to health care providers of orthopedic and prosthetic medical devices. In these, patients were grouped according to the type of OPMD and surveyed on the services of the health care provider, rather than satisfaction on their OPMD (Bosmans, Geertzen, \& Dijkstra, 2009; Geertzen, Gankema, Groothoff, \& Dijkstra, 2002). A further study focused on patient satisfaction with OPMD and the high satisfaction with orthopedic and prosthetic medical devices services (Magnusson, Ahlström, Ramstrand, \& Fransson, 2013). This study examined the same characteristics of medical devices as this study, but was to patients with amputated limbs because of cancer. In this, an understanding of the regular use of OPMD, and the comfort felt by the wearer, were involved in improving the prognosis for patients returning to normal working life (Pezzin, Dillingham, MacKenzie, Ephraim, \& Rossbach 2004). The best comparison with our results involves the study of Bravin et al. (2014), which also revealed an overall high patient satisfaction with OPMD. In addition, when analyzing individual key factors of the OPMD, weight and fit rated the highest in patient satisfaction, and comfort and appearance the lowest (Bravini et al., 2014). The above findings are in line with our conclusions.

\section{Conclusion}

This study of patient satisfaction with orthosis and prosthesis medical devices provided an indication of patient satisfaction with OPMD in areas such as the weight, fit, durability, pain, abrasiveness, easy of application, comfort, and appearance. It revealed that the weight and fit of OPMD gave the greatest patient satisfaction. Similarly, it revealed that the comfort and appearance of the OPMD were characteristics that provided lower patient satisfaction, and therefore, are areas to improve in terms of the quality management of OPMD by the health care facilities. Identification of key areas in the management of quality will contribute to improving services and quality of life for patients.

\section{Acknowledgement}

This contribution/publication is the result of the project implementation: Comenius University in Bratislava Science Park supported by the Research and Development Operational Programme funded by the ERDF / Grant number: ITMS 26240220086. Project is co-financed from EU sources.
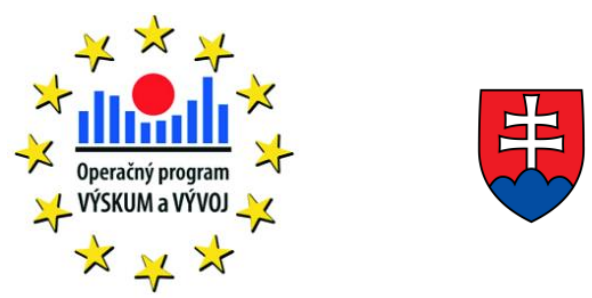

MINISTERSTVO ŠKOLSTVA VEDY, VYSKUMU A ŠPORTU SLOVENSKEJ REPUBLIKY

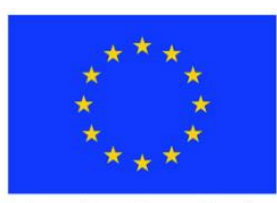

Európska únia 


\section{References}

Berke, G. M, Fergason, J., Milani, J.R., Hattingh, J., McDowell, M., Nguyen, V., \& Reiber, G. E. (2010). Comparison of satisfaction with current prosthetic care in veterans and service members from Vietnam and OIF/OEF conflicts with major traumatic limb loss. Journal of Rehabilitation Research \& Development, 47, 361-372.

Bosmans, J., Geertzen, J., \& Dijkstra, P. U. (2009). Consumer satisfaction with the services of prosthetics and orthotics facilities. Prosthetics and Orthotics International, 33, 69-77.

Bravini, E., Franchignoni, F., Ferriero, G., Giordano, A., Bakhsh, H., Sartorio, F., \& Vercelli, S. (2014). Validation of the Italian version of the Client Satisfaction with Device module of the Orthotics and Prosthetics Users' Survey. Disability and Health Journal, 7, 442-447.

FDA. (2014). Is the product a medical device? Retrieved from: http://www.fda.gov/MedicalDevices/DeviceRegulationand Guidance/Overview/ClassifyYourDevice/ucm051512.htm.

Geertzen, J. H. B., Gankema, H. G. J., Groothoff, J. W., \& Dijkstra, P. U. (2002). Consumer satisfaction in prosthetics and orthotics facilities. Prosthetics and Orthotics International, 26, 64-71.

Heinemann, A. W., Bode, R. K., \& O'Reilly, C. (2003). Development and measurement properties of the Orthotics and Prosthetics Users' Survey (OPUS): a comprehensive set of clinical outcome instruments. Prosthetics and Orthotics International, 27, 191-206.

Karmarkar, A. M., Collins, D. M., Wichman, T., Franklin, A., Fitzgerald, S. G., Dicianno, B. E., Pasquina, P. F., \& Cooper, R. A. (2009). Prosthesis and wheelchair use in veterans with lower-limb amputation. Journal of Rehabilitation Research \& Development, 46, 567-576.

Jarl, G. M., \& Hermansson, L. M. N. (2009). Translation and linguistic validation of the Swedish version of Orthotics and Prosthetics Users' Survey. Prosthetics and Orthotics International, 33, 329-338.

Jarl, G. M., Heinemann, A W, \& Hermansson, L. M. N. (2012). Validity evidence for a modified version of the Orthotics and Prosthetics Users' Survey. Disability and Rehabilitation Assistive Technology, 7, 469-478.

Jarl, G. M., Holmefur, M., \& Hermansson, L. M. N. (2014). Test-retest reliability of the Swedish version of the Orthotics and Prosthetics Users' Survey. Prosthetics and Orthotics International, 38, 21-26.

Magnusson, L, Ahlström, G, Ramstrand, N, \& Fransson, E. (2013). Malawian prosthetic and orthotic users mobility and satisfaction with their lower limb assistive device. Journal of Rehabilitation Medicine, 45, 385-391.

Pezzin, L. E., Dillingham, T. R., \& MacKenzie, E. J., Ephraim P., Rossbach P. (2004). Use and satisfaction with prosthetic limb devices and related services. Archives of Physical Medicine and Rehabilitation, 85, 723-9.

Sastri, V. R. (2014). 2 - Regulations for Medical Devices and Application to Plastics Suppliers: History and Overview. In V. R. Sastri (Ed.), Plastics in Medical Devices (Second Edition) (pp. 9-18). Oxford: William Andrew Publishing. 